\title{
Process for Bimetallic Slab of Aluminium Alloy under the Level DC Electromagnetic Field
}

\author{
Xuepeng $\mathrm{GAO}^{1)}$ Tingju $\mathrm{LI}^{2)}$ Caihong $\mathrm{WU},{ }^{1)}$ Yaping $\mathrm{WU}^{1)}$ and Junze $\mathrm{JIN}^{3)}$ \\ 1) Graduate Student of Laboratory of Special Processing of Raw Materials, Dalian University of Technology, Dalian 116024 , \\ China. E-mail: gaoxuepeng2000@sina.com $\quad$ 2) State Key Laboratory of Materials Modification, Dalian University of \\ Technology, Dalian 116024, China. E-mail: tjuli@dlut.edu.cn 3 3) Laboratory of Special Processing of Raw Materials, \\ Dalian University of Technology, Dalian 116024, China.
}

(Received on December 12, 2005; accepted on March 10, 2006)

\begin{abstract}
In this paper, the EMBR technique was applied in producing the bimetallic slab on the basis of numerical simulation with the software of ANSYS. By suppressing the mixture of two kinds of molten metals in the mold of continuous casting strand with a level DC electromagnetic field, the bimetallic slab of Al-12wt\% Si and $\mathrm{Al}-10 \mathrm{wt} \% \mathrm{Mg}$ was obtained. The slab was analyzed by XRD, EPMA and metalloscope. The results showed that there were same compositions on two sides of the slab obtained without electromagnetic field and there were different compositions on two sides of the slab obtained with electromagnetic field of $0.15 \mathrm{~T}$, no obvious interface was found in the slab. The conclusion indicated that the electromagnetic field restrained the flow of the melt effectively.
\end{abstract}

KEY WORDS: EMBR; bimetallic slab; continuous casting; numerical simulation.

\section{Introduction}

Bimetallic material has been used widely in aviation, petroleum, chemistry, shipbuilding and automotive industries and becomes one of research focuses in material field. At present, the methods for manufacturing bimetallic slabs are summarized as follows: ${ }^{1}$ hot pressure welding, diffusing welding or bonding, hot roll bonding, cold roll bonding, explosion welding and continuous casting. In these fabrication methods, continuous casting is particularly ideal because of favorable interface bond. However, it is difficult to cast bimetallic slab continuously because of the turbulent flow and the fluid jet of molten metals. ${ }^{2}$ In order to solve the difficulties, electromagnetic field has been applied to suppress the mixture of two kinds of molten metals from two nozzles. ${ }^{3-7)}$ In this paper, the flow field affected by electromagnetic field was computed with the software of ANSYS in order to gain reasonable technological parameters. On the basis of the calculation results, model experiments of continuous casting of $\mathrm{Al}-12 \mathrm{wt} \% \mathrm{Si}$ and $\mathrm{Al}-$ $10 \mathrm{wt} \% \mathrm{Mg}$ bimetallic slab were conducted.

\section{Principle of Process}

The continuous casting process of bimetallic slab with $\mathrm{EMBR}^{3-20)}$ (Electromagnetic Brake) is schematically illustrated in Fig. 1. A level DC electromagnetic field is imposed outside a mold. A steel baffle is put in the middle of the mold. Two kinds of molten metals of different chemical compositions are supplied simultaneously through submerged entry nozzles into the left and right pools in the mold respectively. By imposing level DC electromagnetic field, the resultant braking force (Lorentz force) is expected to act on the flows to prevent the mixture of the two kinds of molten metals under the baffle in the mold.

Figure 2 shows the principle of EMBR. It bases on two basic laws. ${ }^{6,7)}$

The one is that the flow of molten metal in the electromagnetic field conducts inductive current:

$$
J=\sigma v \times B=\left(\sigma v B_{z}, 0,0\right) .
$$

where $\sigma$ is electrical conductivity, $v$ is the flow velocity and $B$ is magnetic flux density.

The other is that the electromagnetic force $F_{\text {em }}$ is generated in the fluid liquid metal under the electromagnetic field:

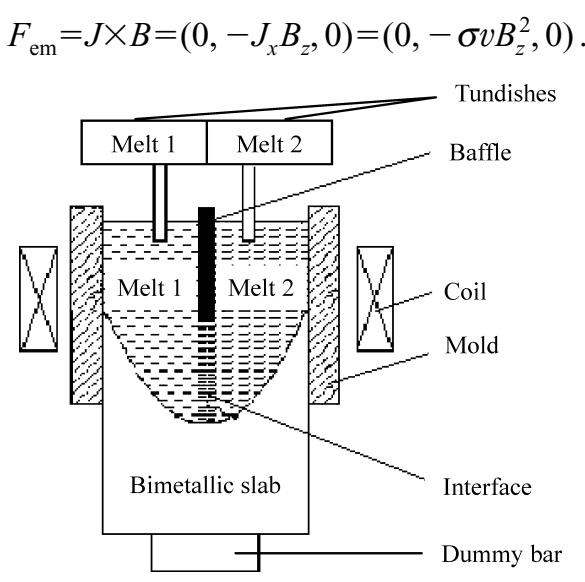

Fig. 1. Schematic diagram of continuous casting process for bimetallic slab with EMBR. 


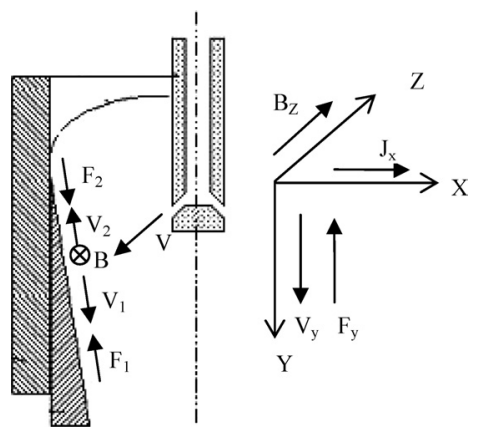

Fig. 2. Theoretic schematic diagram of EMBR.

where the "-" denotes the opposite directions of the electromagnetic force and the flow of the liquid metal. The electromagnetic force can suppress the molten metal flow.

Theoretically, Maxwell equation, Navier-Stokes equation and energy equation should be coupled to analyze the flow field pattern in the mold under EMBR. Since the flow velocity is low in general, the magnetic Reynolds number of the system is smaller enough than unity. This means that the effect of fluid flow on the magnetic field is negligible. And the electrical parameter is little affected by the temperature. Therefore, the electromagnetic field can be calculated separately.

The electromagnetic field distribution was computed by the software of ANSYS. Considering the boundary condition that the magnetic lines of force were parallel in the infinite distance, the distribution of magnetic flux density $B$ in the section which paralleled to the narrow-face direction and crossed the mold axis could be calculated. The electromagnetic force $F_{\text {em }}$ which was derived from the substitution of $B$ into Eq. (2) was considered as volume force in momentum equation and was used as the source term of discrete equation.

\section{Numerical Simulation}

Assume the liquid metal was an incompressible fluid and was uniform and isotropic in electrical properties. The velocity field were computed with the $k-\varepsilon$ turbulence model, ${ }^{20,21)}$ in which the wall function and the free slip condition were employed at the solidification front and at the meniscus, respectively. Choose the two-dimensional section which paralleled to the wide-face direction and crossed the mold axis as the modeling section to calculate the flow field. Thomas et $a l^{22,23)}$ considered that in fact the flow in the mold was three-dimensional and the flow patterns were closely connected with the nozzle's angle. Most of metal fluid jets from the nozzle flowed downward and upward when the angle was downward, so the model was simplified to two-dimension. ${ }^{24)}$ The simplification could minimize the computing measurements, reduce the difficulties, save the computing time and was reasonable. $\mathrm{Al}-12 \mathrm{wt} \% \mathrm{Si}$ alloy was selected as simulation material and the upper mold was selected as braking area. The parameters used in calculation process are listed in Table $\mathbf{1 .}$

\subsection{Governing Equations}

Using the assumptions above, the governing equations
Table 1. Parameters for numerical simulation.

\begin{tabular}{lll}
$2650 \mathrm{~kg} / \mathrm{m}^{3}$ & Specific conductance & $4.08 \times 10^{5} /(\Omega \cdot \mathrm{m})$ \\
$1005 \mathrm{~J} /(\mathrm{kg} \cdot \mathrm{K})$ & Entrance velocity & $240 \mathrm{~mm} / \mathrm{s}$ \\
$1.30 \times 10^{-3} \mathrm{~kg} /(\mathrm{m} \cdot \mathrm{s})$ & Casting speed & $3.5 \mathrm{~mm} / \mathrm{s}$ \\
$167.47 \mathrm{~W} /(\mathrm{m} \cdot \mathrm{K})$ & Pouring temperature & $973 \mathrm{~K}$ \\
$75 \mathrm{~mm} \times 50 \mathrm{~mm} \times 150 \mathrm{~mm}$ & & \\
\hline
\end{tabular}

that described the incompressible quasi-stable state fluid were presented as follows ${ }^{6,7,20,21,25)}$ :

1. Continuity equation:

$$
\frac{\partial u}{\partial x}+\frac{\partial v}{\partial y}=0
$$

2. Momentum equation:

$$
\begin{aligned}
& \rho\left(u \frac{\partial u}{\partial x}+v \frac{\partial u}{\partial y}\right) \\
& \quad=-\frac{\partial p}{\partial x}+\left[\frac{\partial}{\partial x}\left(\mu_{T} \frac{\partial u}{\partial x}\right)+\frac{\partial}{\partial y}\left(\mu_{T} \frac{\partial u}{\partial y}\right)\right]-\sigma u B^{2}
\end{aligned}
$$

$$
\begin{aligned}
& \rho\left(u \frac{\partial v}{\partial x}+v \frac{\partial v}{\partial y}\right) \\
& =-\frac{\partial p}{\partial y}+\left[\frac{\partial}{\partial x}\left(\mu_{T} \frac{\partial v}{\partial x}\right)+\frac{\partial}{\partial y}\left(\mu_{T} \frac{\partial v}{\partial y}\right)\right]+g-\sigma u B^{2}
\end{aligned}
$$

3. Turbulent kinetic energy equation:

$$
\begin{aligned}
& \rho\left(u \frac{\partial k}{\partial x}+v \frac{\partial k}{\partial y}\right) \\
& =\frac{\partial}{\partial x}\left(\frac{\mu_{T}}{P_{r k}} \frac{\partial k}{\partial x}\right)+\frac{\partial}{\partial y}\left(\frac{\mu_{T}}{P_{r k}} \frac{\partial k}{\partial y}\right)+G-\rho \varepsilon
\end{aligned}
$$

4. Dissipation rate of turbulent kinetic energy:

$$
\begin{aligned}
& \rho\left(u \frac{\partial \varepsilon}{\partial x}+v \frac{\partial \varepsilon}{\partial y}\right) \\
& \quad=\frac{\partial}{\partial x}\left(\frac{\mu_{T}}{P_{r k}} \frac{\partial \varepsilon}{\partial x}\right)+\frac{\partial}{\partial y}\left(\frac{\mu_{T}}{P_{r k}} \frac{\partial \varepsilon}{\partial y}\right)+C_{1} G \frac{\varepsilon}{k}-C_{2} \rho \frac{\varepsilon^{2}}{k}
\end{aligned}
$$

where

$$
\begin{gathered}
G=\mu_{T}\left[2\left(\frac{\partial u}{\partial x}\right)^{2}+\left(\frac{\partial v}{\partial y}\right)^{2}+2\left(\frac{\partial u}{\partial y}+\frac{\partial v}{\partial x}\right)^{2}\right], \\
\mu_{T}=\frac{C_{\mu} \rho k^{2}}{\varepsilon}
\end{gathered}
$$

Constants used in the $k-\varepsilon$ model: $C_{1}=1.44, C_{2}=1.92$, $C_{\mu}=0.09, P_{\mathrm{rk}}=1.0, P_{r \varepsilon}=1.3$. 


\subsection{Boundary Conditions}

1. At the inlet of the nozzle:

$$
u=0, \quad v=v_{\text {in }}, \quad k=0.05 v_{\text {in }}^{2}, \quad \varepsilon=0.1 k^{2}
$$

2. At the outlet of the nozzle:

$$
\frac{\partial u}{\partial y}=\frac{\partial v}{\partial y}=\frac{\partial k}{\partial y}=\frac{\partial \varepsilon}{\partial y}=u=0
$$

3. At the solid surface:

$$
\frac{\partial u}{\partial y}=\frac{\partial v}{\partial y}=\frac{\partial k}{\partial y}=\frac{\partial \varepsilon}{\partial y}=0
$$

4. At the steadfast wall of the mold:

$$
\begin{gathered}
\frac{\partial u}{\partial x}=\frac{\partial k}{\partial x}=\frac{\partial \varepsilon}{\partial x}=0 \\
\begin{cases}\Gamma=\mu & x^{+}<11.5 \\
\Gamma=\frac{\mu x^{+}}{2.5 \ln \left(9 x^{+}\right)} & x^{+} \geq 11.5\end{cases}
\end{gathered}
$$

where

$$
x^{+}=\frac{\rho k^{1 / 2} C_{\mu}^{1 / 4} x}{\mu}, \quad \varepsilon=\frac{\left(C_{\mu} k^{2}\right)^{3 / 4}}{0.4 x}
$$

\subsection{Results}

Figure 3 shows the effect of magnetic flux density on the flow in the mold. Two kinds of molten metals without the level DC electromagnetic field mixed together as shown in Fig. 3(a). After the molten metals entered the mold, two dispersive currents upward and downward were formed because the fluid jets were strained by the narrow-face. With the function of gravity and viscosity force, two inverse flow areas were formed. In the lower area the fluid jets were strong and in the upper area the meniscus was instable because the molten metals flowed.

When the magnetic flux density of $0.1 \mathrm{~T}$ was imposed, the flow field pattern was hardly changed. The two inverse flow areas still existed as shown in Fig. 3(b). But the flow velocity and the depth of the fluid jets were diminution.

When the magnetic flux density of $0.15 \mathrm{~T}$ was imposed, the above-mentioned inverse flows were suppressed basically as shown in Fig. 3(c). The flow velocity was further diminution, the inverse flow areas were disappeared basically and the depth and intensity of the fluid jets were decreased simultaneously.

When the magnetic flux density upped to $0.2 \mathrm{~T}$, the depth of the fluid jets was still diminishing but the variation was limited as shown in Fig. 3(d). The higher magnetic flux density was, the more current energy demanded. So the magnetic flux density of $0.15 \mathrm{~T}$ was much more reasonable considering the energy consumption and the effect of EMBR.

From the above analysis, the flow field pattern was strongly affected by the magnetic flux density. The level DC electromagnetic field not only diminished the depth of the fluid jets but also controlled the inverse flow areas in the
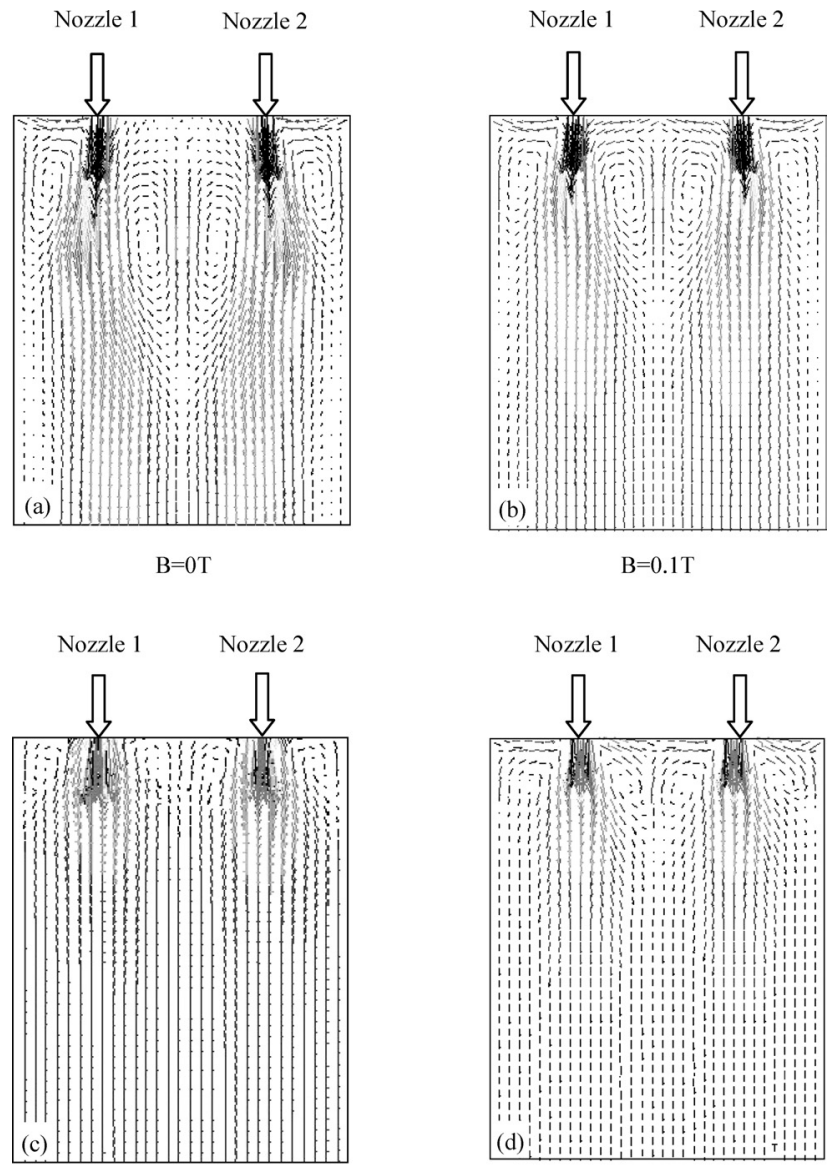

$\mathrm{B}=0.15 \mathrm{~T}$

$\mathrm{B}=0.2 \mathrm{~T}$

Fig. 3. Computed distribution of flow field in the mold with different magnetic flux density: (a) $B=0 \mathrm{~T}$, (b) $B=0.1 \mathrm{~T}$, (c) $B=0.15 \mathrm{~T}$, (d) $B=0.2 \mathrm{~T}$.

mold. With the increase of the magnetic flux density, the inverse flow areas were diminished and upper shift.

\section{Experiment}

\subsection{Experimental Apparatus and Procedure}

Figure 4 shows the experimental apparatus. Two tundishes were laid in a rectangular container. A water cooling copper mold with its inner cross section of $75 \mathrm{~mm} \times 50 \mathrm{~mm}$ and its height of $150 \mathrm{~mm}$ was used in this experiment. The level DC electromagnetic field was imposed outside the mold.

The experimental conditions are presented in Table 2. $\mathrm{Al}-12 \mathrm{wt} \% \mathrm{Si}$ alloy and $\mathrm{Al}-10 \mathrm{wt} \% \mathrm{Mg}$ alloy were melted in a resistance furnace respectively, and were kept at the temperature of $973 \mathrm{~K}$ in the two tundishes. During continuous casting, the two molten alloys were simultaneously poured into the mold through two nozzles respectively.

\subsection{Results and Discussion}

In order to analyze conveniently, the samples of different slabs were taken and were signed as shown in Fig. 5. The slab obtained under $0 \mathrm{~T}$ was marked as number 1 , the slab obtained under $0.1 \mathrm{~T}$ was marked as number 2 and the slab obtained under $0.15 \mathrm{~T}$ was marked as number 3 ; the sample taken from the left part of the slab was marked as letter L, the sample taken from the middle part of the slab was 


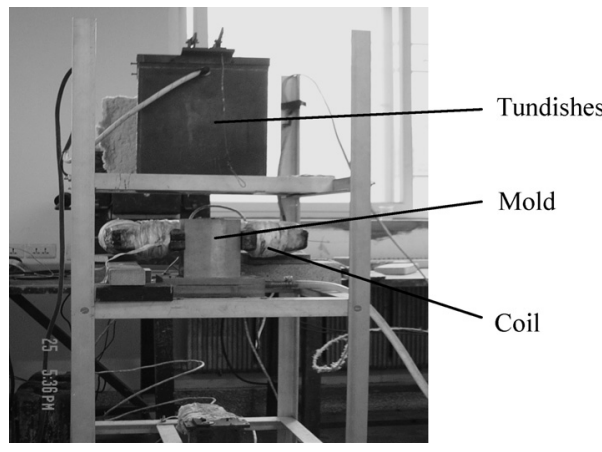

Fig. 4. Experimental apparatus.

Table 2. Experimental conditions.

\begin{tabular}{ll}
\hline Alloys & Al-12wt\%Si \& Al-10wt\%Mg \\
Magnetic flux density & $0 \mathrm{~T}, 0.1 \mathrm{~T}, 0.15 \mathrm{~T}$ \\
Pouring temperature & $973 \mathrm{~K}$ \\
Cooling water flux & $380 \mathrm{~L} / \mathrm{h}$ \\
Mold lubricant & silicone oil \\
Baffle size & $2 \mathrm{~mm} \times 60 \mathrm{~mm} \times 45 \mathrm{~mm}$ \\
Casting speed & $3.5 \mathrm{~mm} / \mathrm{s}$ \\
\hline
\end{tabular}
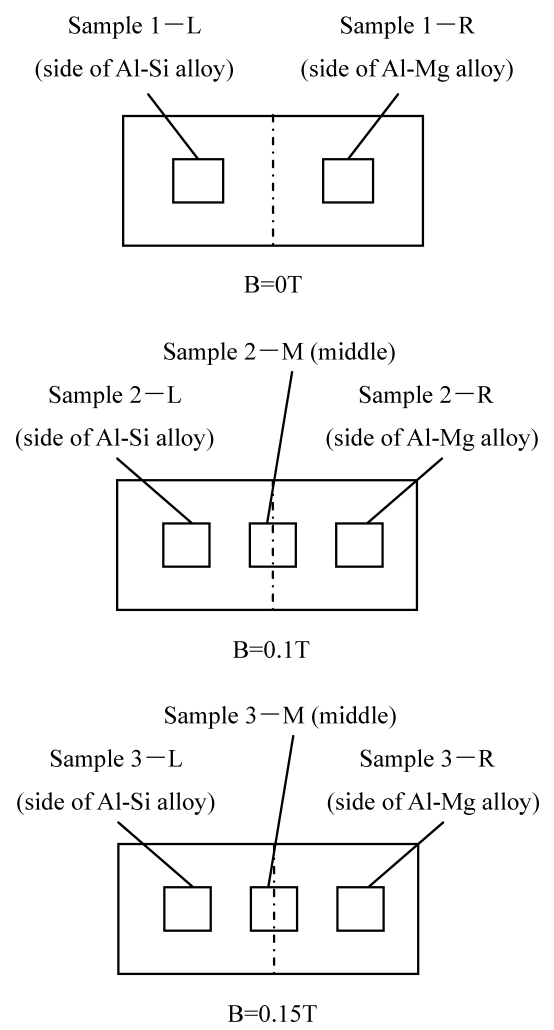

Fig. 5. Schematic diagram of samples with different magnetic flux density.

marked as letter $\mathrm{M}$ and the sample taken from the right part of the slab was marked as letter R. So the samples were signed as 1-L (side of Al-Si alloy), 1-R (side of Al-Mg alloy), 2-L (side of Al-Si alloy), 2-M (middle), 2-R (side of Al-Mg alloy), 3-L (side of Al-Si alloy), 3-M (middle) and $3-\mathrm{R}$ (side of $\mathrm{Al}-\mathrm{Mg}$ alloy). And the size of samples was $15 \mathrm{~mm} \times 15 \mathrm{~mm} \times 15 \mathrm{~mm}$.

Figures 6-8 give the results analyzed by powder X-ray diffraction. The images of Fig. 6(a) (sample 1-L) and Fig.

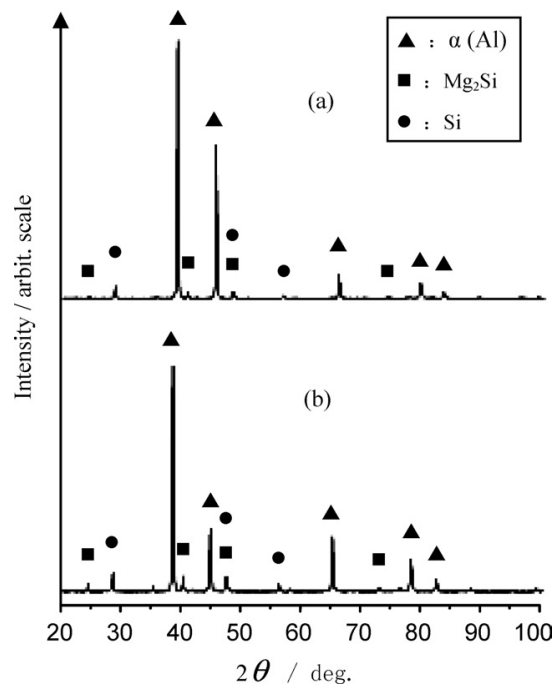

Fig. 6. XRD images of bimetallic slab under $B=0 \mathrm{~T}$ : (a) sample 1-L (side of Al-Si alloy) and (b) sample 1-R (side of Al-Mg alloy).

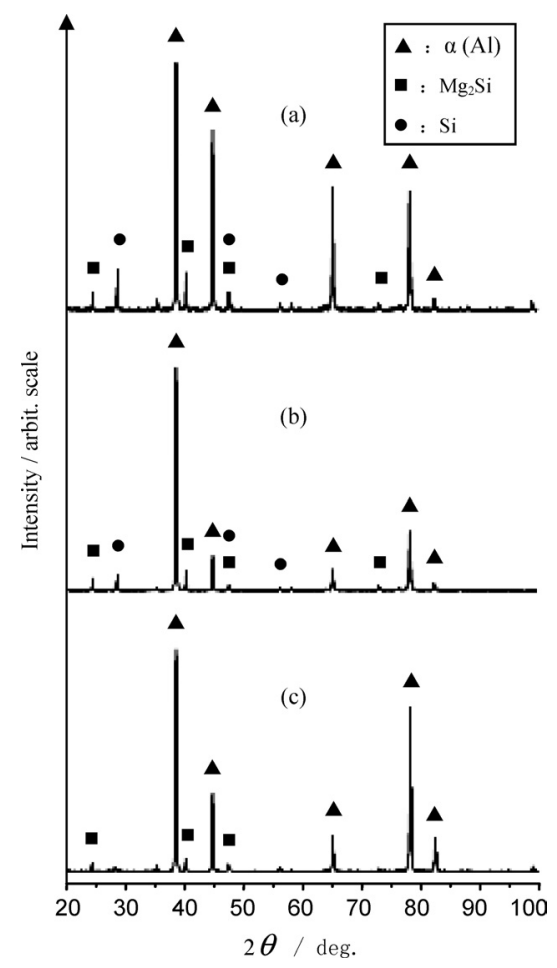

Fig. 7. XRD images of bimetallic slab under $B=0.1 \mathrm{~T}$ : (a) sample 2-L (side of Al-Si alloy), (b) sample 2-M (middle) and (c) sample 2-R (side of Al-Mg alloy).

6(b) (sample 1-R) were quite similar. They contained same phases including $\alpha(\mathrm{Al}), \mathrm{Mg}_{2} \mathrm{Si}$ and simple substance $\mathrm{Si}$. So it was considered that the two kinds of molten metals mixed together without the level DC electromagnetic field.

When the magnetic flux density of $0.1 \mathrm{~T}$ was imposed, $\alpha$ (Al), $\mathrm{Mg}_{2} \mathrm{Si}$ and simple substance $\mathrm{Si}$ existed simultaneously as shown in Fig. 7(a) (sample 2-L) and Fig. 7(b) (sample $2-\mathrm{M})$. But there were only $\alpha(\mathrm{Al})$ and $\mathrm{Mg}_{2} \mathrm{Si}$ except simple substance $\mathrm{Si}$ in sample $2-\mathrm{R}$ as shown in Fig. 7(c). This phenomenon indicated that the $\mathrm{Si}$ concentrations in the $\mathrm{Al}-10 \mathrm{wt} \% \mathrm{Mg}$ side were too few to form simple substance $\mathrm{Si}$. According to the analysis above, it was considered that when the magnetic flux density was $0.1 \mathrm{~T}$, the electromag- 
netic force was not enough to suppress the turbulent flow and the fluid jets effectively.

When the magnetic flux density of $0.15 \mathrm{~T}$ was imposed, the three images were different obviously as shown in Figs. 8(a)-8(c). Figure 8(a) showed sample 3-L contained $\alpha$ (Al) and $\mathrm{Si}$, Fig. 8(b) showed sample 3-M contained $\alpha(\mathrm{Al})$, $\mathrm{Mg}_{2} \mathrm{Si}$ and $\mathrm{Si}$ and Fig. 8(c) showed there were only $\alpha(\mathrm{Al})$ and a new phase $\mathrm{Al}_{3} \mathrm{Mg}_{2}$ in sample $3-\mathrm{R}$. This phenomenon indicated that the mixture of the two kinds of molten metals

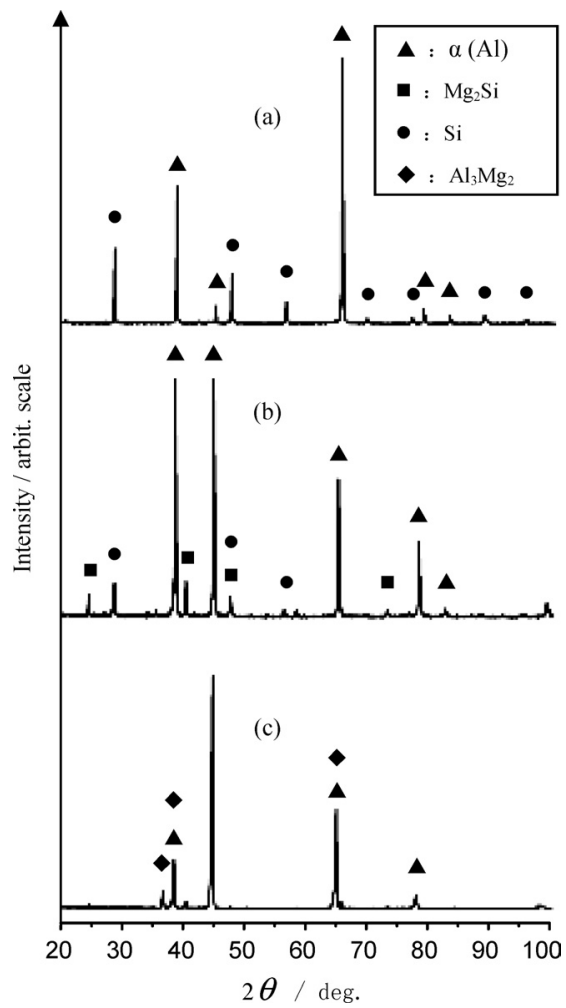

Fig. 8. XRD images of bimetallic slab under $B=0.15 \mathrm{~T}$ : (a) sample 3-L (side of Al-Si alloy), (b) sample 3-M (middle) and (c) sample 3-R (side of Al-Mg alloy).

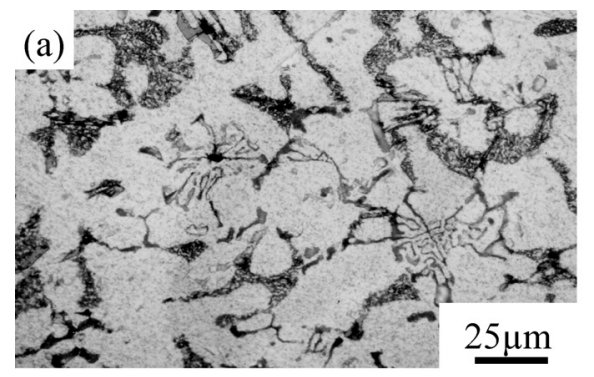

was suppressed effectively and ideal bimetallic slab was obtained.

Figures 9-11 show the microstructures of bimetallic slabs with different magnetic flux density. The microstructures of Fig. 9(a) (sample 1-L) and Fig. 9(b) (sample 1-R) were quite similar. The results of EPMA indicated that the white part was the matrix $\alpha$ (Al) with the Al concentrations of approximately $95.7 \%$, the $\mathrm{Mg}$ concentrations of $4 \%$ and the $\mathrm{Si}$ concentrations of $0.3 \%$; the black part was $\mathrm{Al}-\mathrm{Si}$ eutectic structure with the $\mathrm{Si}$ concentrations of $8 \%$ and the $\mathrm{Al}$ concentrations of $92 \%$; the phase like fishbone appearing in the grain boundary of $\alpha(\mathrm{Al})$, compared with the XRD analysis, was the hardening constituent $\mathrm{Mg}_{2} \mathrm{Si}$ with the $\mathrm{Si}$ concentrations of $35 \%$ and the $\mathrm{Mg}$ concentrations of $65 \%$. From the above analysis, when the level DC electromagnetic field was not imposed, the two kinds of molten metals mixed together.

The fishbone structure $\mathrm{Mg}_{2} \mathrm{Si}$ was simultaneously contained in Fig. 10(a) (sample 2-L), Fig. 10(b) (sample 2-M) and Fig. 10(c) (sample 2-R). And Al-Si eutectic structure was found obviously in Fig. 10(a) (sample 2-L) and Fig. 10 (b) (sample 2-M) with the Si concentrations of $12 \%$ by EPMA. But in Fig. 10(c) (sample 2-R) no Al-Si eutectic structure was found. This compared well with the results of XRD.

The microstructures in Figs. 11(a)-11(c) were different completely. Figure 11(a) (sample 3-L) contained $\alpha$ (Al) and $\mathrm{Si}$, Fig. 11(b) (sample 3-M) contained $\alpha$ (Al), Al-Si eutectic structure and $\mathrm{Mg}_{2} \mathrm{Si}$ and Fig. 11(c) (sample 3-R) contained $\alpha(\mathrm{Al})$ and $\mathrm{Al}_{3} \mathrm{Mg}_{2}$. The results indicated that no element $\mathrm{Mg}$ existed in Fig. 11(a) (sample 3-L) and no element Si existed in Fig. 11(c) (sample 3-R). Through the above analysis, when the magnetic flux density of $0.15 \mathrm{~T}$ was imposed, the mixture of the two kinds of molten metals was suppressed effectively. This compared well with the result of numerical simulation.

Figure 12 shows the concentrations distribution of $\mathrm{Si}$

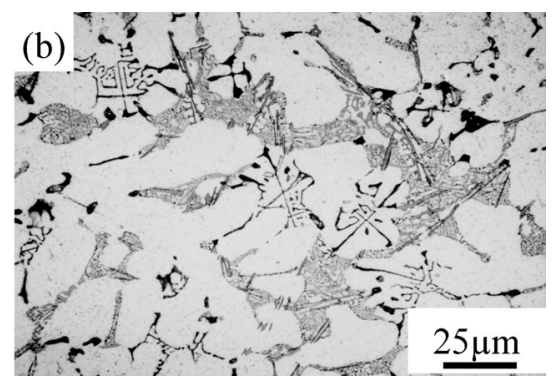

Fig. 9. Microstructures of samples with the magnetic flux density of $0 \mathrm{~T}$ : (a) sample 1-L (side of Al-Si alloy) and (b) sample 1-R (side of Al-Mg alloy).
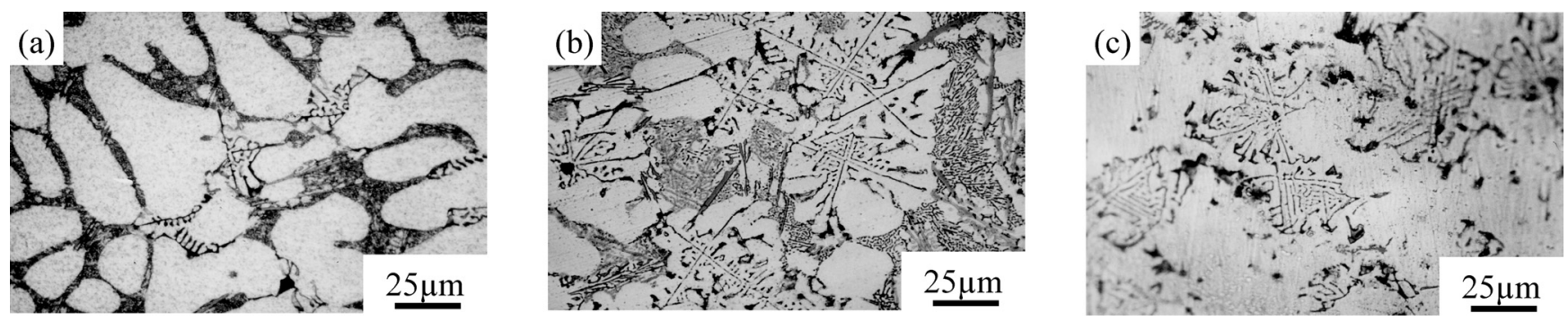

Fig. 10. Microstructures of samples with the magnetic flux density of 0.1 T: (a) sample 2-L (side of Al-Si alloy), (b) sample 2-M (middle) and (c) sample 2-R (side of Al-Mg alloy). 

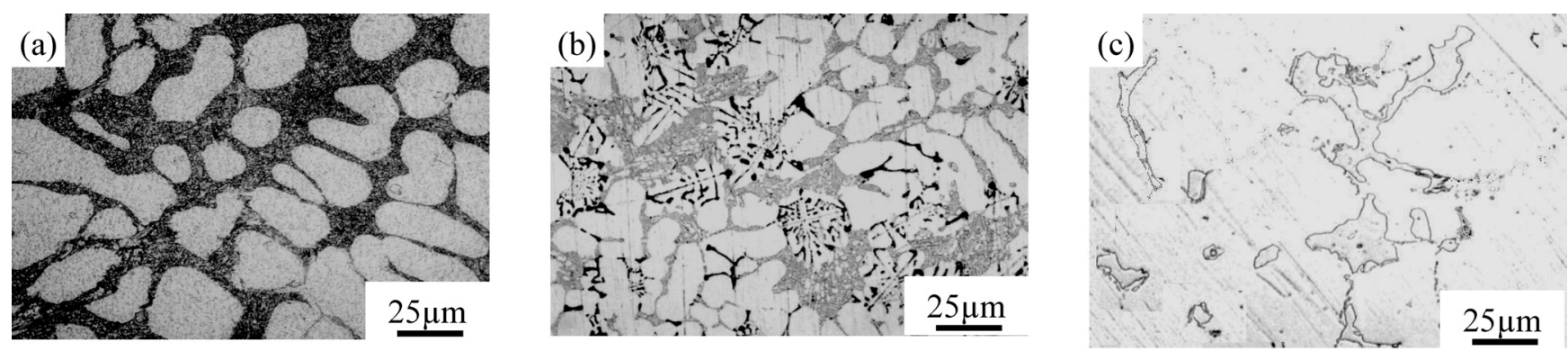

Fig. 11. Microstructures of samples with the magnetic flux density of $0.15 \mathrm{~T}$ : (a) sample 3-L (side of Al-Si alloy), (b) sample 3-M (middle) and (c) sample 3-R (side of Al-Mg alloy).

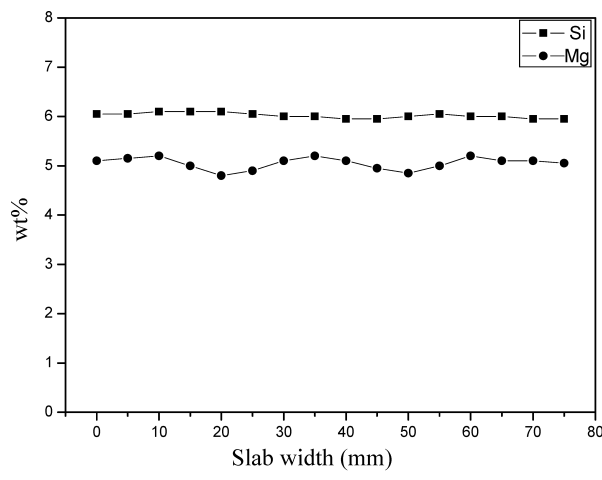

(a) $\mathrm{B}=0 \mathrm{~T}$

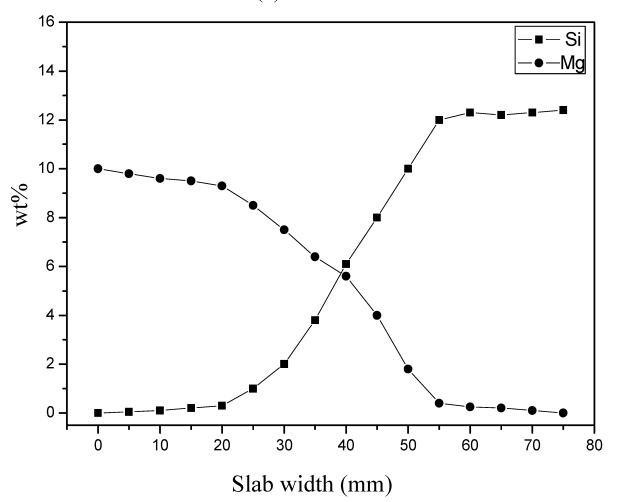

(b) $\mathrm{B}=0.15 \mathrm{~T}$

Fig. 12. The concentrations distribution of $\mathrm{Si}$ and $\mathrm{Mg}$ of the bimetallic slabs: (a) $B=0 \mathrm{~T}$ and (b) $B=0.15 \mathrm{~T}$.

and $\mathrm{Mg}$ in width direction of the cast slabs under different conditions. As shown in Fig. 12(a), when the magnetic flux density of $0 \mathrm{~T}$ was imposed, the concentrations of both $\mathrm{Si}$ and $\mathrm{Mg}$ were relatively homogeneous. When the magnetic flux density of $0.15 \mathrm{~T}$ was imposed, the concentrations of Si was higher in the right part than in the left part and the concentrations of $\mathrm{Mg}$ was higher in the left part than in the right part of the slabs as shown in Fig. 12(b). The bimetallic slab was obtained.

\section{Conclusions}

(1) The numerical simulation of molten metal flow in the mold affected by electromagnetic field is conducted. When the magnetic flux density is greater than or equal to $0.15 \mathrm{~T}$, the effect on the molten metal flow is obvious.

(2) The level DC magnetic field can not only suppress the flow velocity and diminish the depth of the fluid jets but also control the inverse flow areas in the mold.
(3) In the condition of pouring temperature of $973 \mathrm{~K}$, casting speed of $3.5 \mathrm{~mm} / \mathrm{s}$, cooling water flux of $380 \mathrm{~L} / \mathrm{h}$ and the magnetic flux density of $0.15 \mathrm{~T}$, the bimetallic slab of $\mathrm{Al}-12 \mathrm{wt} \% \mathrm{Si}$ alloy and $\mathrm{Al}-10 \mathrm{wt} \% \mathrm{Mg}$ alloy is finally obtained.

\section{Acknowledgement}

This work was supported by the National Natural Science Foundation of China, Project No. 50071015 and Project No. 50474055.

\section{REFERENCES}

1) G. Y. Tzou and M. N. Huang: J. Mater. Process. Technol., 140 (2003), 622.

2) M. Y. Ha, H. G. Lee and S. H. Seong: J. Mater. Process. Technol., 133 (2003), 322.

3) H. Harada, E. Takeuchi, M. Zeze and H. Tanaka: Appl. Math. Model., 22 (1998), 873.

4) E. Takeuchi, M. Zene, H. Tanaka, H. Harada and S. Mizoguchi: Ironmaking Steelmaking, 24 (1997), 257.

5) E. Takeuchi, H. Tanaka and H. Kajioka: Int. Symp. on Electromagnetic Processing Materials, ISIJ, Tokyo, Japan, (1994), 364.

6) T. J. Li, Y. H. Zhao, B. Wen and J. Z. Jin: Ironmaking Steelmaking, 29 (2002), 337.

7) C. H. Wu, F. Jia, T. J. Li and J. Z. Jin: Asia-Euro Workshop on Electromagnetic Processing of Materials, Northeastern University, Shenyang, China, (2004), 77.

8) A. Idogawa, M. Sugizawa, S. Takeuchi, K. Sorimachi and T. Fujii: Mater. Sci. Eng. A, A173 (1993), 293.

9) M. J. Cho, S. J. Kim, I. C. Kim, J. K. Kim, D. W. Cha, J. S. Kim and J. H. Park: The 3rd Int. Symp. on Electromagnetic Processing Materials, ISIJ, Tokyo, Japan, (2000), 176.

10) H. A. Wouters, R. P. J. Duursma, A. A. Kamperman and W. F. M. Damen: The 3rd Int. Symp. on Electromagnetic Processing Materials, ISIJ, Tokyo, Japan, (2000), 182.

11) A. F. Lehman, G. R. Tallback, S. G. Kollberg and H. R. Hackl: Int. Symp. on Electromagnetic Processing Materials, ISIJ, Tokyo, Japan, (1994), 372.

12) A. Idogawa, H. Tozawa, S. Takeuchi, K. Sorimachi, T. Fujii, M. Sugizawa and T. Yahiro: Int. Symp. on Electromagnetic Processing Materials, ISIJ, Tokyo, Japan, (1994), 378.

13) D. W. van der Plas, W. H. L. Moonen, P. Biesboer and C. Platvoet: Int. Symp. on Electromagnetic Processing Materials, ISIJ, Tokyo, Japan, (1994), 384.

14) P. Gardin, J.-M. Galpin, M.-C. Regnier and J.-P. Radot: Int. Symp. on Electromagnetic Processing Materials, ISIJ, Tokyo, Japan, (1994), 390.

15) T. Ishii, M. Tanaka, A. Uehara, T. Okazaki, H. Kimura and N. Tsutsumi: Int. Symp. on Electromagnetic Processing Materials, ISIJ, Tokyo, Japan, (1994), 396.

16) M. Morishita, T. Miyake, H. Tokunaga and K. Ebina: Int. Symp. on Electromagnetic Processing Materials, ISIJ, Tokyo, Japan, (1994), 402.

17) H. Harada, K. Okazawa, M. Tanaka and E. Takeuchi: Int. Symp. on 
ISIJ International, Vol. 46 (2006), No. 7

Electromagnetic Processing Materials, ISIJ, Tokyo, Japan, (1994), 414.

18) J. Nagai, K. Suzuki, S. Koshima and S. Kollberg: Iron Steel Eng., 61 (1984), 41.

19) Y. S. Hwang, P. R. Cha, H. S. Nam, K. H. Moon and J. K. Yoon: ISIJ Int., 37 (1997), 659.

20) D. S. Kim, W. S. Kim and K. H. Cho: ISIJ Int., 40 (2000), 670.
21) S. K. Dash, M. Dutta and N. Rajesh: ISIJ Int., 41 (2005), 1059.

22) X. Huang, B. G. Thomas and F. M. Najjar: Metall. Trans. B, B23 (1992), 339.

$23)$ B. G. Thomas, X. Huang and R. C. Sussman: Metall. Mater. Trans. $B, \mathbf{B 2 5}$ (1994), 527.

24) W. S. Hwang and R. A. Stoehr: J. Met., 35 (1983), 22.

25) B. K. Li and F. Tsukhashi: ISIJ Int., 41 (2001), 844. 